\title{
TRES PROYECTOS DE JULIO CANO LASSO EN FUENTELARREINA
}

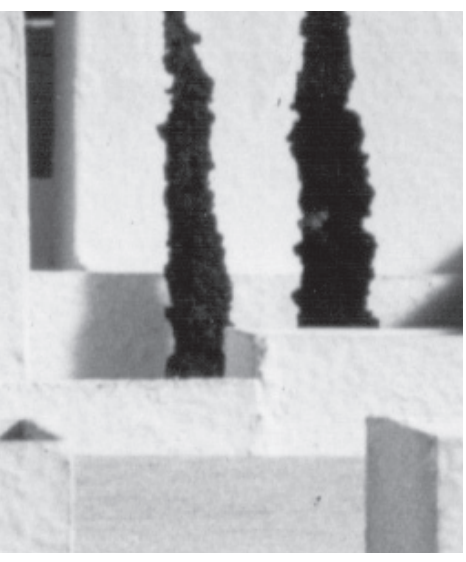

\author{
Inés Martín Robles y Luis Pancorbo Crespo
}

Three projects of Julio Cano Lasso in Fuentelarreina

Boletín Académico. Revista de investigación y arquitectura contemporánea

Escuela Técnica Superior de Arquitectura. Universidade da Coruña

elSSN 2173-6723

wuw.boletinacademico.com

Número 5 (2015)

Páginas 51-60

Fecha de recepción 30.10.2014

Fecha de aceptación 10.12.2014

https://doi.org/10.17979/bac.2015.5.0.1038

\section{Resumen}

El trabajo pretende abordar el análisis del método proyectual de Julio Cano Lasso y buscar relaciones entre su obra y las referencias externas a ella utilizadas por el arquitecto. Este objetivo general se ejemplifica a través del estudio de las herramientas proyectuales concretas usadas en los sucesivos proyectos realizados, junto con Juan Antonio Ridruejo, entre los años 1968 y 1976, para las Oficinas Centrales de Telefónica en Fuentelarreina. Estos tres proyectos, con un programa que va variando en el tiempo y con distintas localizaciones dentro de una extensa parcela, se desarrollan partiendo de esquemas organizativos completamente diferentes, que surgen sin embargo de un método proyectual homogéneo que hemos denominado «método referencial».

\section{Abstract}

This paper intends the analysis of Julio Cano Lasso's design method and search for relationships between his work and the external references selected by the architect. It is made through the study of the tools used in three subsequent projects, done along with Juan Antonio Ridruejo, between 1968 and 1976 for the Telefónica Headquarters in Fuentelarreina. These three projects, with a program that varies in time with different locations within an extensive plot, are developed on entirely different organizational schemes, however arising of a homogeneous design method that we have called «reference method».

\section{Palabras clave}

Ciudad histórica, Arquitectura popular, Metodología proyectual, Método referencial, Paisaje

\section{Keywords}

Historic Towns, Vernacular Architecture, Project Methodology, Reference Method, Landscape 

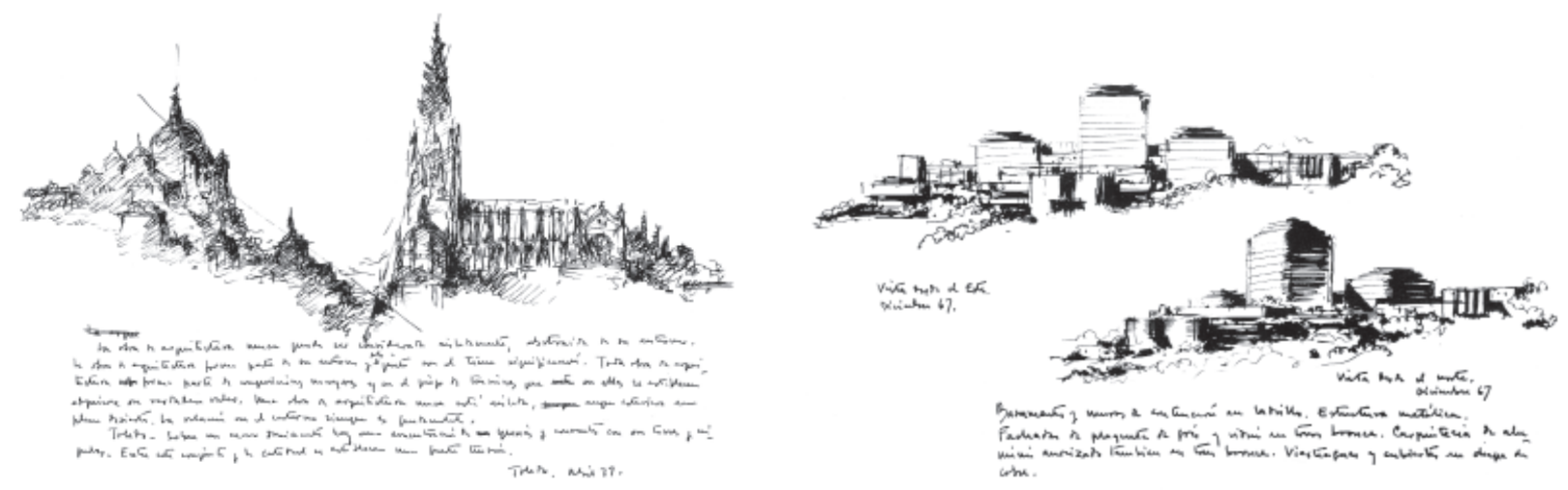

01 Julio Cano Lasso, dibujo de Toledo, 1977

02 Julio Cano Lasso, Sede Social de Telefónica, propuesta 1, Fuentelarreina (Madrid), 1968; concurso

\section{LA CIUDAD HISTÓRICA Y SU PAISAJE COMO REFERENCIA}

«A primera vista, la obra de Julio Cano Lasso muestra un frecuente recurso: el cúmulo de cúpulas, torres, edificios — una ciudad - desafiando el borde de un abismo o situados sobre una meseta, las formas de los edificios mezclándose con las formas de la naturaleza.

»Es el sentimiento del paisaje clásico el que entra en juego: una catedral, un acantilado rocoso, un viaducto, árboles aislados... todos ellos uniéndose contribuyendo igualmente-, para la formación de una imagen.

"Esta aparición es a menudo la base desde la que comienza la construcción del proyecto, a veces coincidiendo con la realidad misma - una realidad extraordinaria-del lugar (pienso en los proyectos de Madrid, Salamanca y Cuenca), otras veces constituyéndose en la virtualidad de una aspiración, capaz de llevar al éxito a proyectos y obras bien fundamentados» ${ }^{1}$.

La cita de Francesco Venezia se selecciona por su certero análisis de uno de los campos referenciales de las afinidades electivas de Julio Cano para el desarrollo proyectual: la ciudad histórica. Viendo sus edificios de programa más complejo y mayor tamaño, producto muchas veces de un sistema de composición por partes, se observa, no ya una perfecta integración dentro del conjunto de la ciudad histórica, como en los casos de los palacios de congresos de Salamanca y Santiago de Compostela, sino algo que va más allá. Los pro- yectos se alimentan de la referencia a la ciudad como organismo y se convierten ellos mismos en pequeñas ciudades, en las que aparecen redes de vías, espacios públicos y edificios de mayor escala que se ofrecen como hitos al igual que lo hacen en la ciudad los edificios públicos e institucionales cuando emergen entre el caserío uniforme.

Es ésta una estrategia de raíz clásica proveniente de la "casa como una ciudad y la ciudad como una casa" albertiana, que retomarán en los años 60 y 70, con renovado énfasis, ciertos grupos de arquitectos, críticos con la objetualidad excesiva del Movimiento Moderno.

Efectivamente, esta actitud está emparentada estrechamente con las experiencias sobre el microurbanismo de la tercera generación moderna, como el Team $\mathrm{X}$, con sus propuestas basadas en las ideas de cluster y mat-building. Estos conceptos partían de las tesis estructuralistas, en las que la importancia del conjunto reside en la relación entre los elementos, y no en los elementos en sí. Alison Smithson da una definición clave y una serie de ejemplos muy claros de esta nueva actitud en su escrito de 1974 «How to recognise and Read Mat-Building ${ }^{2}$.

Se trata, pues, de un acercamiento híbrido entre el nivel urbano y el del edificio, en el que se busca la flexibilidad de usos por parte del usuario, la ambigüedad funcional, el reforzamiento del sentido de pertenencia y comunidad; una nueva gradación, más matizada, en las condiciones de privacidad de los espacios, y una forma abierta y susceptible de cambio. 

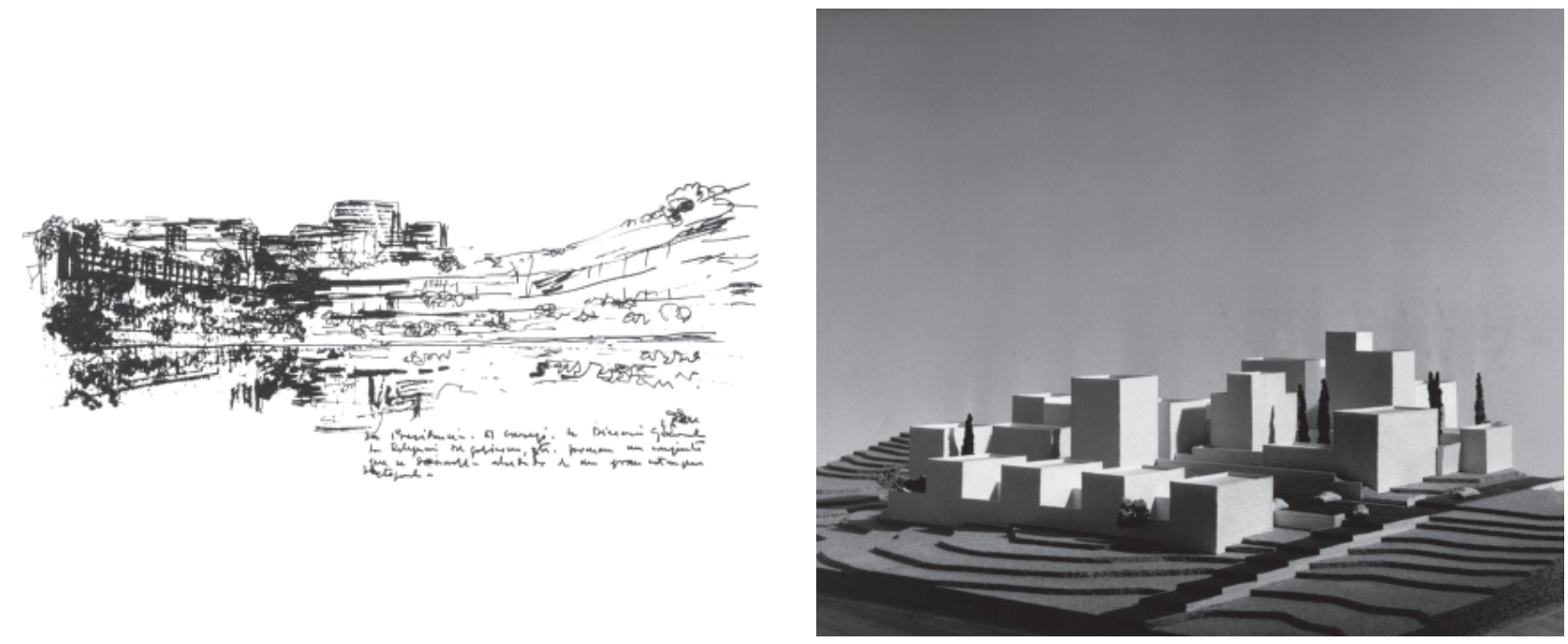

03 Julio Cano Lasso, Sede Social de Telefónica, propuesta 3, Fuentelarreina (Madrid), 1976; concurso 04 Julio Cano Lasso, concurso para El Saler (Valencia), 1962

En el caso de Julio Cano hay además una importante variación, la valoración del paso del tiempo y la reintegración del nuevo organismo al ambiente natural. Como se puede ver, por ejemplo, en los dibujos de las diferentes propuestas para el concurso de Telefónica en Fuentelarreina, siempre está presente esta voluntad de que lo construido se funda en el paisaje circundante mediante varias operaciones proyectuales, con la utilización de un profuso ajardinamiento en los espacios entre edificios y sobre las propias edificaciones, y con un manejo del concepto de lugar por parte del arquitecto extraordinariamente matizado y complejo (Fig. 01-03).

Perfectos ejemplos de este tipo de proyectos son, además de las propuestas en Fuentelarreina, las Universidades Laborales de Almería, Ourense y Albacete, y los concursos para Maspalomas y El Saler. En todos estos proyectos, la referencia a la ciudad histórica no sólo cumple una función de catalizador proyectual, sino que de ella, el arquitecto extrae, en total sintonía con la filosofía del primer pragmatismo de principios del siglo XX, herramientas operativas que le sirven tanto para sus proyectos como para dar una solución a los problemas de crecimiento de los núcleos urbanos de su época. La analogía se establece con los procesos de conformación de la ciudad, de los que extrae dos tipos de operación dialéctica que luego instrumentaliza: la dialéctica entre unidad y fragmentación, y la existente entre el edificio y el lugar (Fig. 04-05).

El primer par dialéctico es básico también para la comprensión de la ciudad histórica, en la que la suma de estratos temporales, de edificios de diferentes escalas realizados por diferentes agentes, se integran en un todo orgánico gracias al efecto compactante de la tradición, el clima y la disponibilidad y optimización de los sistemas constructivos y de los materiales. En este apartado se podría incluir la tensión siempre existente en la ciudad entre los polos de fragmentación y unidad - debido a la dualidad entre la masa dominante del caserío anónimo-y la presencia imponente y monumental de los edificios de carácter público.

La dialéctica entre edificio y lugar vendría a ser la traducción literal de la síntesis entre ambos elementos, expresada por Julio Cano en su libro sobre las ciudades históricas y su paisaje: "Arraigadas en la tierra, forman parte de la geografía. Construir es colaborar con la naturaleza y el paisaje, y la ciudad antigua se implanta en el paisaje realzándolo de diversas maneras: las defensas militares, fosos, muros y baluartes, subrayan sus perfiles más agrestes; los edificios nobles acentúan poderosos el relieve, y la edificación popular y anónima se apiña al resguardo de las murallas y en los lugares más protegidos, abriendo sus fachadas al sol y a las buenas orientaciones y volviendo la espalda a los vientos hostiles.

"La incorporación al paisaje se produce de manera natural. El paso del tiempo va fundiendo arquitectura y naturaleza en el mismo color y materia; al fin y al cabo, la misma piedra y la misma arcilla; de tal manera, que llega a ser difícil distinguir lo natural de la obra de los hombres» ${ }^{3}$ (Fig. 06-07). 


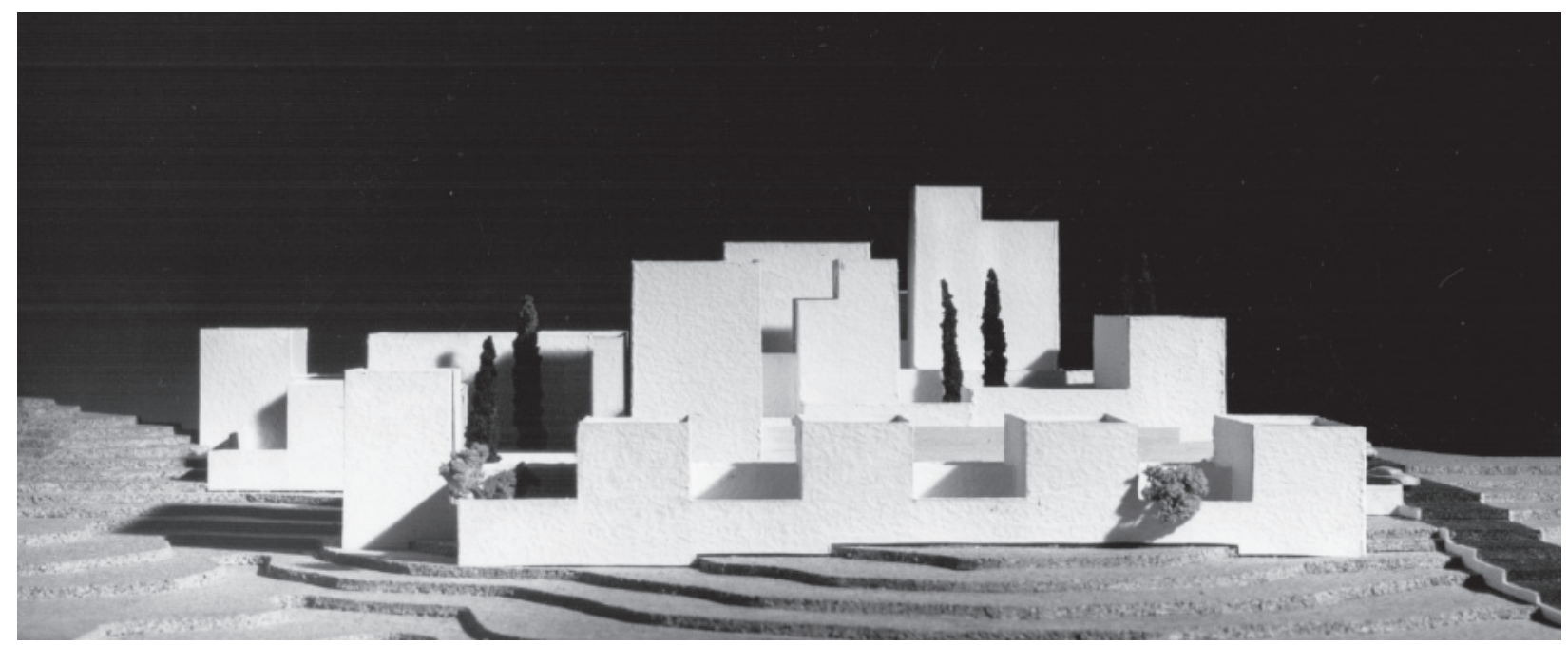

05 Julio Cano Lasso, concurso para El Saler (Valencia), 1962

Esta instrumentalización de los sentidos, más o menos ocultos de las referencias usadas por el arquitecto, es especialmente clara en el caso que nos ocupa debido a una característica especial no compartida con el resto de archipiélagos referenciales, como pueden ser la referencia a la ruina o a obras del Movimiento Moderno. En este caso, las imágenes referenciales usadas por Julio Cano han sido también producidas por él, como resultado de un minucioso trabajo de investigación y análisis sobre la evolución morfológica de las ciudades y de la percepción de su relación con el entorno natural circundante. Esta investigación, que el autor insiste en desvincular del urbanismo, es en su mayor parte llevada a cabo por medio del dibujo en su libro «La ciudad y su paisaje» (cf. nota 3). El libro se compone de dibujos reelaborados numerosas veces que sirven al arquitecto como intermediarios o traductores entre el proyecto arquitectónico y la realidad percibida del modelo real, o de dibujos antiguos que dan fe de la situación de las ciudades estudiadas a lo largo de la historia (Antón van den Wyngaerde, Joris Hoefnagel, Goya o Texeira). Es decir, en este caso la referencia ya ha sido reelaborada; es una referencia derivada, en la que su esencia útil para el trabajo posterior es más explícita y clara.

\section{LAS PROPUESTAS PARA EL CONCURSO DE FUENTELARREINA}

Como hemos dicho con anterioridad, dentro de la producción de Julio Cano Lasso hay varios proyectos que se podrían adscribir con facilidad a esta línea de estrategia proyectual. Entre ellos están las tres pro- puestas sucesivas que Cano Lasso realizó en los años 1968, 1973 y 1976, conjuntamente con José Antonio Ridruejo, para la sede corporativa central de Telefónica, en Fuentelarreina, Madrid ${ }^{4}$.

Estos proyectos tienen una serie de características espaciales que los convierten en importantes para nuestra exploración del método proyectual de Cano. En primer lugar, suponen la rara oportunidad de repensar y rehacer el proyecto del mismo edificio varias veces, con una separación temporal lo suficientemente amplia que permite distinguir los procedimientos metodológicos debidos a la coyuntura temporal de los verdaderos invariantes proyectuales del arquitecto. En segundo lugar, permite valorar el efecto que las pequeñas variaciones en el programa y en la localización del edificio provocan en el orden proyectual. Paradójicamente, esto es debido a la aplicación de los mismos instrumentos proyectuales en cada propuesta, obtenidos de la referencia a las ciudades históricas y a la arquitectura popular, como son la gradación en la tensión entre fragmentación y unidad, la dialéctica entre el edificio y el paisaje, y la sustentabilidad como herramienta proyectual, siendo los resultados diferentes en el nivel morfológico.

La primera propuesta, del año 1968, tenía como condicionantes una situación en la cima de una cornisa topográfica, unos difusos parámetros urbanísticos (sólo se define un coeficiente de edificabilidad de 0,2 $\mathrm{m} 3 / \mathrm{m} 2$ y la recomendación de no construir en altura) y un programa que comprendía la dirección de la compañía, la agrupación de todos los servicios técni- 

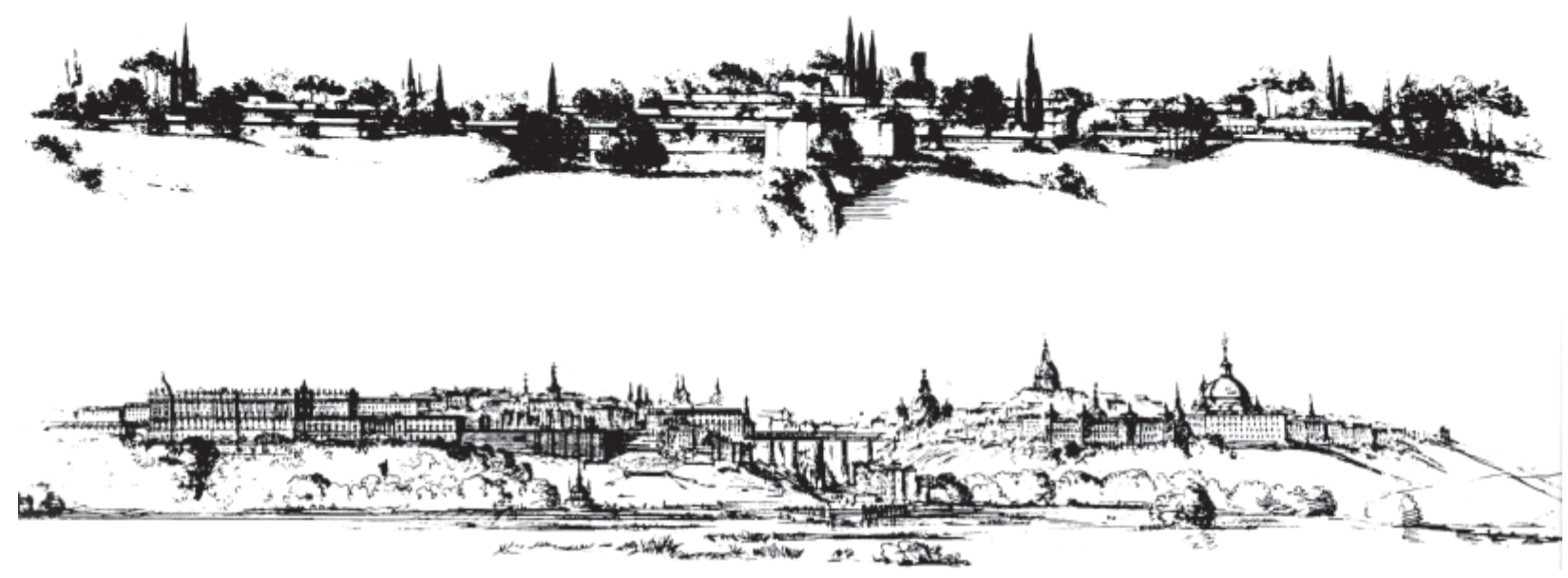

06 Julio Cano Lasso, Sede Social de Telefónica, propuesta 2, Fuentelarreina (Madrid), 1973; concurso 07 Julio Cano Lasso, dibujo de Madrid a principios del siglo XX

cos y administrativos de Madrid, una escuela técnica, un centro de investigación, un club de empleados y una central telefónica.

La primera referencia que utilizan los arquitectos en la memoria del proyecto remite ya a dos de los invariantes del método proyectual de Julio Cano: la referencia a la ciudad y la referencia a la arquitectura popular. «Imaginemos algo así como la Alhambra adaptada a su distinta función (...) La naturaleza penetra entre los distintos edificios hasta patios y jardines interiores, situados en distintos niveles adaptados a la topografía. En nuestro clima seco, el agua es un delicado elemento arquitectónico que utilizaremos en estanques, albercas, canalillos y surtidores $»^{5}$ (Fig. 08).

Como siempre en el arquitecto, las referencias son portadoras de herramientas proyectuales inherentes a ellas. En este ejemplo se puede ver cómo la referencia a la arquitectura popular se ve articulada por medio del uso del agua y de la propia disposición de las edificaciones, formando patios y espacios sombreados y recogidos como medios de acondicionamiento ambiental. Por otro lado, la referencia a la ciudad histórica se despliega aquí en varias herramientas combinadas, entre las que destaca la dialéctica entre unidad y fragmentación. La planta del conjunto se nos presenta como claramente urbana, con una serie de edificios independientes (aunque unidos subterráneamente por corredores) y una serie de espacios exteriores de diferentes escalas que funcionan como los espacios públicos de una ciudad. Esta planta disgregada se expresa en unos alzados en los que los cambios de escala entre los diversos volúmenes producen un perfil variado, diagonalizado y escalonado, que busca la tensión hacia un carácter unitario por medio de un tratamiento material y de huecos horizontales uniforme, y por la inserción de vegetación entre las edificaciones, que amalgaman un conjunto a la vez diverso y unitario (Fig. 09).

El programa presenta también esta ambivalencia urbana. Por un lado, las oficinas horizontales funcionan como el caserío de pequeña escala, y los cuerpos cilíndricos ciegos de ladrillo de las rampas y contenciones, como una fortificación perimetral. Sin presencia individual, se muestran como una masa neutra que recoge en su interior los patios y plazas públicas. Por otro lado, las partes del programa dedicadas a la alta dirección de la empresa toman el protagonismo volumétrico demandado por la correcta correspondencia con su uso. Se producen así surgimientos de verticalidad y mayor escala sobre el frente continuo, presentando al exterior el perfil escalonado y variado de una ciudad histórica.

En el año 1973 se redactó la segunda propuesta. Para entonces ya existía una normativa urbanística aprobada para la zona, que permitía el mismo volumen construido sobre rasante que se consideró en la anterior propuesta pero restringía la altura de la edificación seis metros sobre la rasante del terreno natural. El nuevo programa, a su vez, variaba respecto al anterior en la supresión del centro de investigación y la escuela técnica. La ubicación dentro de la parcela era la misma que en la propuesta previa. 

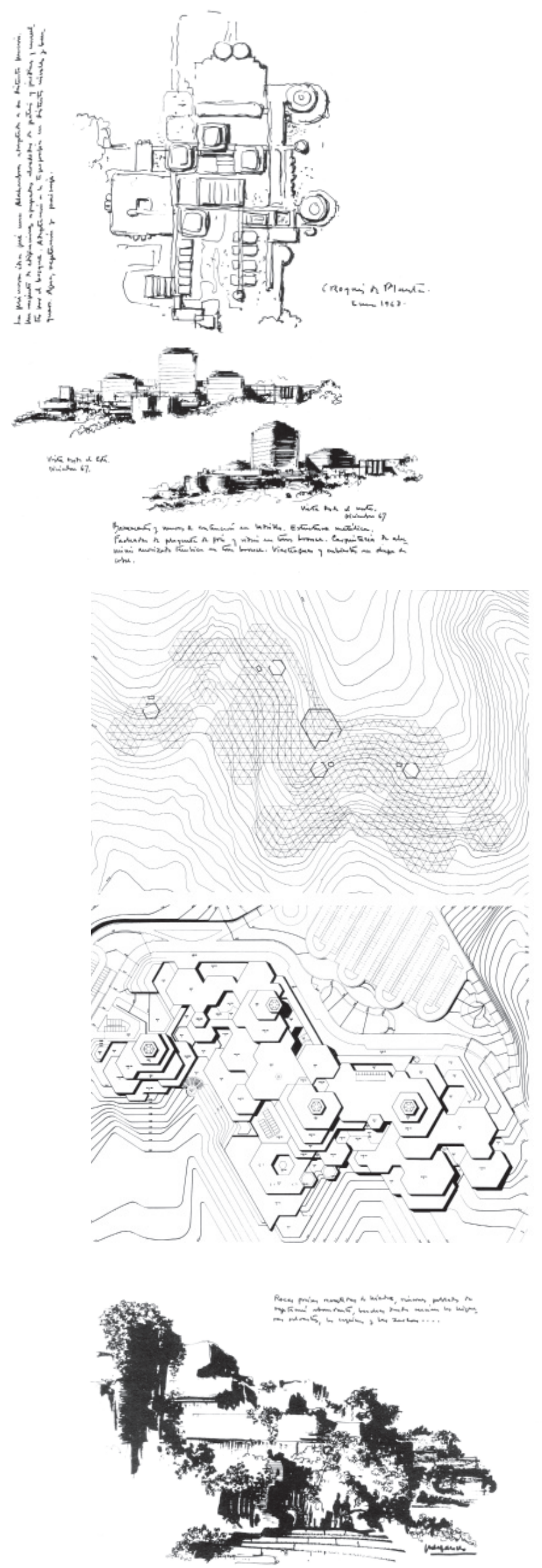
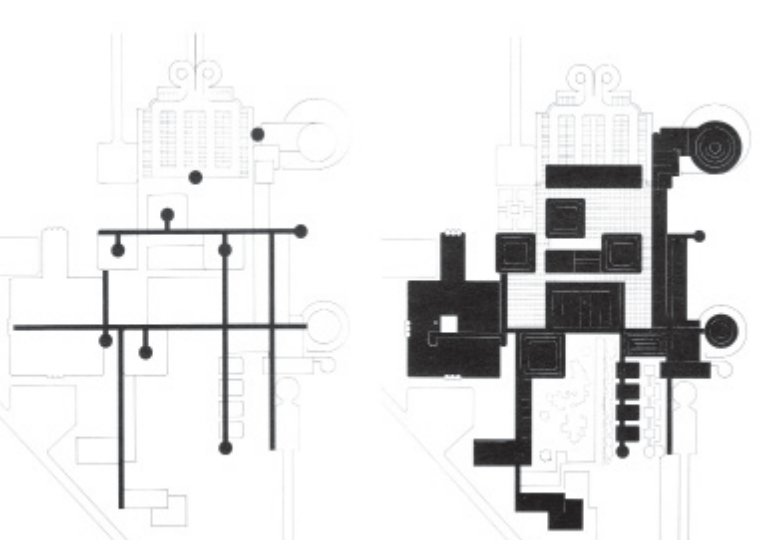

08 Julio Cano Lasso, Sede Social de Telefónica, propuesta 1, Fuentelarreina (Madrid), 1968; croquis

09 Sede Social de Telefónica, propuesta 1; anteproyecto

10 Sede Social de Telefónica, propuesta 2, 1973; plantas

11 Sede Social de Telefónica, propuesta 2; vistas
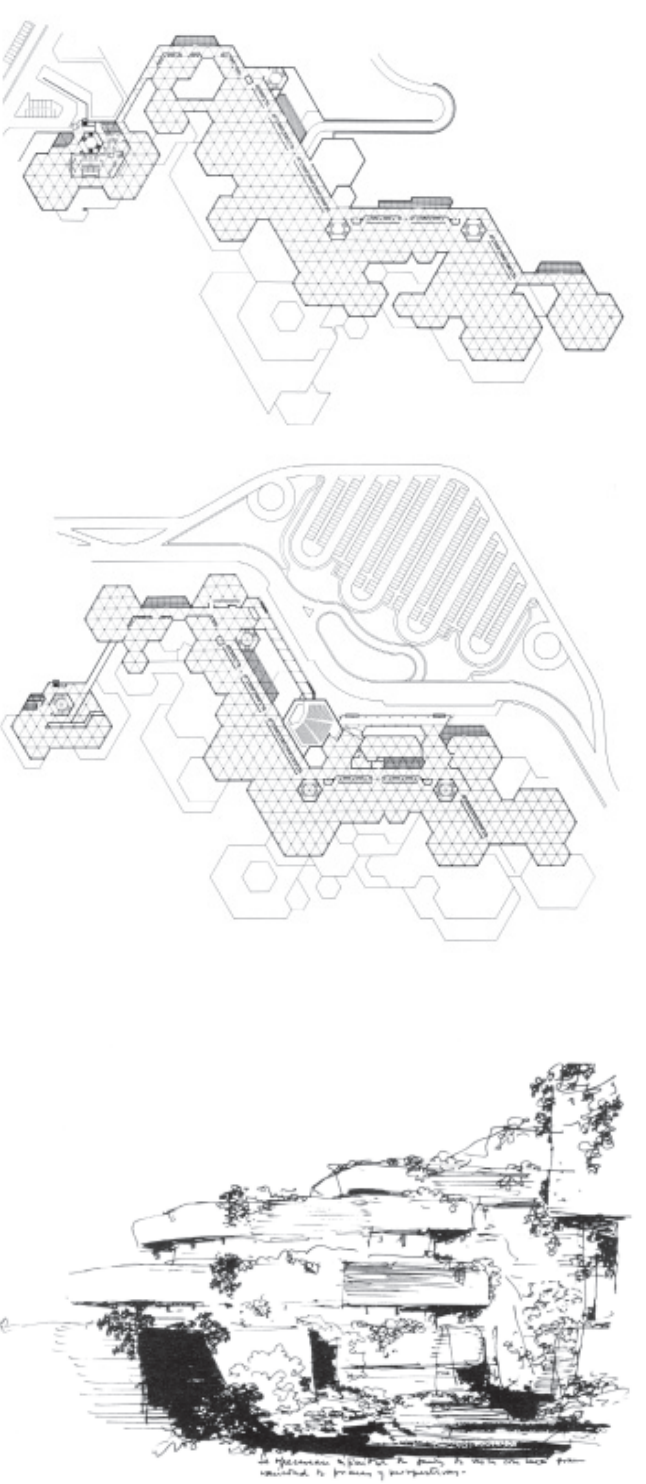

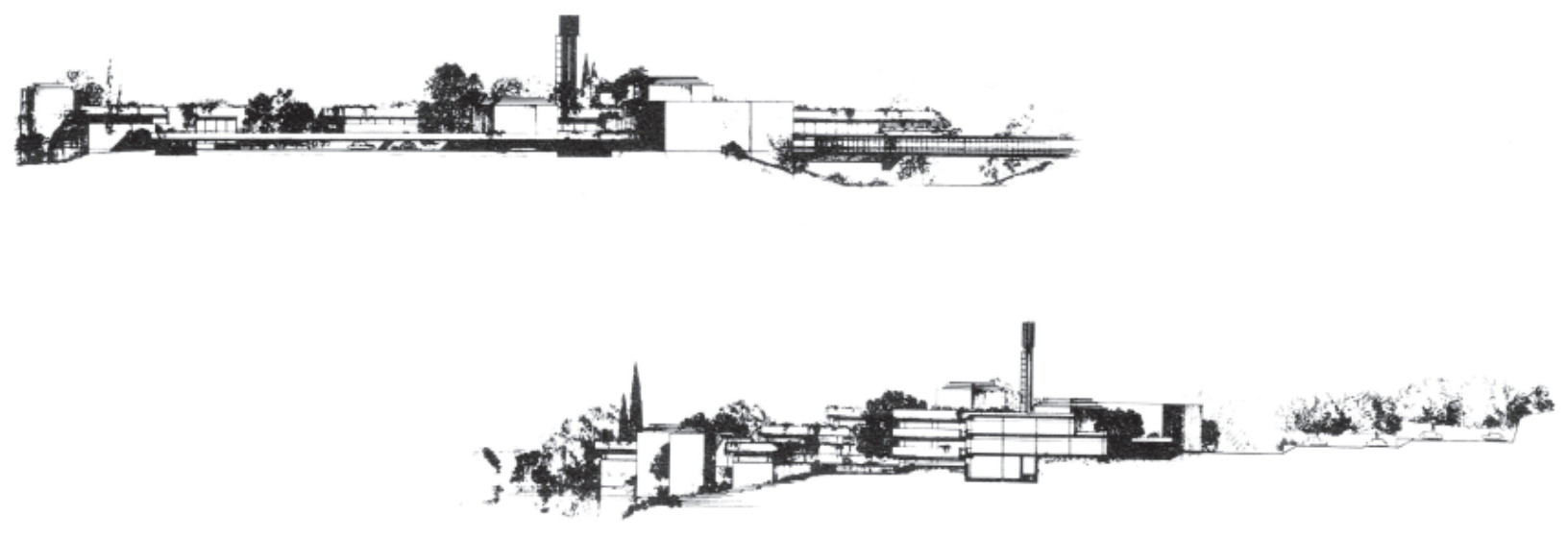

12 Sede Social de Telefónica, propuesta 2; alzados

La restricción de la altura supuso inmediatamente la necesidad de compactar el edificio en planta, por lo que se pasa de un esquema de piezas separadas a un único edificio que conforma una topografía escalonada dentro del paisaje. Buscando una mayor integración con la topografía, se adoptó una geometría triangular que organizase el edificio en planta siguiendo las tres direcciones principales marcadas por las curvas de nivel del terreno. La viabilidad de esa geometría para un programa en el que predominaba la oficina paisaje se veía reforzada por el uso del hormigón, cuyo vertido se vería favorecido por los ángulos obtusos obtenidos de la agrupación de triángulos (Fig. 10).

La referencia a la ciudad se ve aquí mediatizada por la consideración de la relación de ésta con espacios naturales de tipo arquitectónico como la ciudad encantada o las hoces y torcas conquenses en las que grandes muros de roca encierran espacios llenos de vegetación y frescor, un paisaje en el que las enormes rocas pulidas por el tiempo adquieren un carácter similar al de las construcciones humanas más abstractas.

La relación con el paisaje en esta propuesta es de total integración, pero a la vez no pierde en ningún momento su carácter urbano. Esta nueva topografía escalonada, llena de patios y terrazas, se ve reforzada con el uso extensivo de las cubiertas ajardinadas que, con una clara voluntad de resolver el acondicionamiento del conjunto, lo convierten en una suerte de ruina urbana invadida por el medio natural. En la silueta de esta nueva ciudad naturalizada los surgimientos de verticalidad desaparecen y son sustituidos por la verticalidad de los cipreses entrelazados con la edificación y dibujados en los alzados. La dialéctica entre unidad y fragmentación se ve resuelta en este proyecto por medio del mayor o menor fraccionamiento del borde del edificio, de carácter casi fractal, que va siendo menos compacto, con elementos quebrados de menor escala según se va ascendiendo, lo que permite una mayor disgregación de las plantas altas y su lectura en las perspectivas como edificios más independientes. Las plantas inferiores se resuelven con un borde menos quebrado formando un basamento pétreo que adquiere el carácter de accidente natural integrado en la orografía original. Se trata, pues, de una gradación vertical de la escala del límite del conjunto (Fig. 11-12).

La tercera propuesta, del año 1976, sufre un cambio de programa más radical. Desaparecen los servicios técnicos y administrativos que suponían la mayor superficie del programa y el edificio pasa a alojar exclusivamente la alta dirección de la empresa y una central telefónica. Este cambio es suficiente para modificar totalmente el proyecto. Al ser menor el edificio, se reubica en un anfiteatro natural bien orientado. Esto lleva a la desaparición de las tres direcciones dominantes en el terreno, lo que a su vez conlleva la desaparición de la trama triangular como rectora de la planta. La eliminación de esta geometría se debe también a planteamientos prácticos, al volverse inapropiada para un programa en el que predominan los despachos cerrados y los espacios compartimentados sobre la oficina paisaje. La nueva topografía condiciona tanto la geometría que ésta varía completamente, pasando a ser lineal, con una condición geométrica predominantemente curva. Se man- 


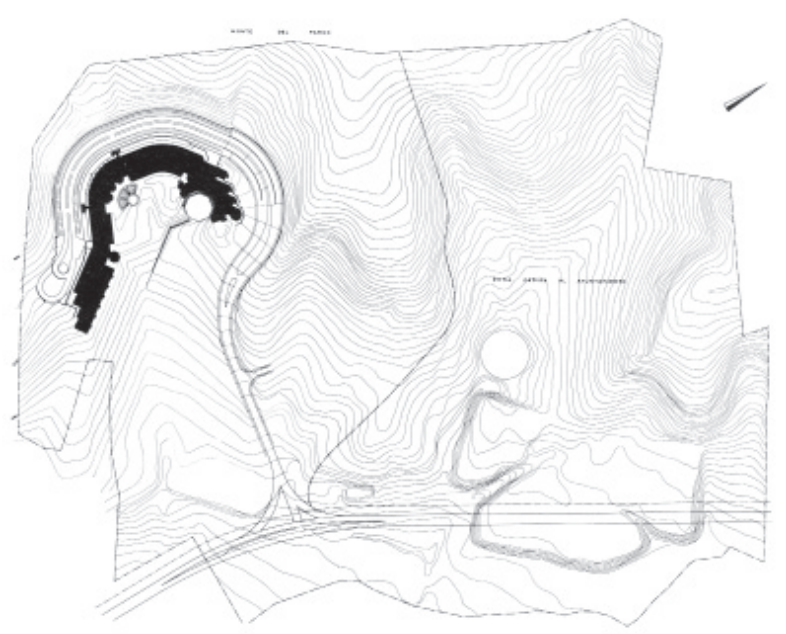

13 Julio Cano Lasso, Sede Social de Telefónica, propuesta 3, 1976: plano de situación

14 Sede Social de Telefónica, propuesta 3; plantas
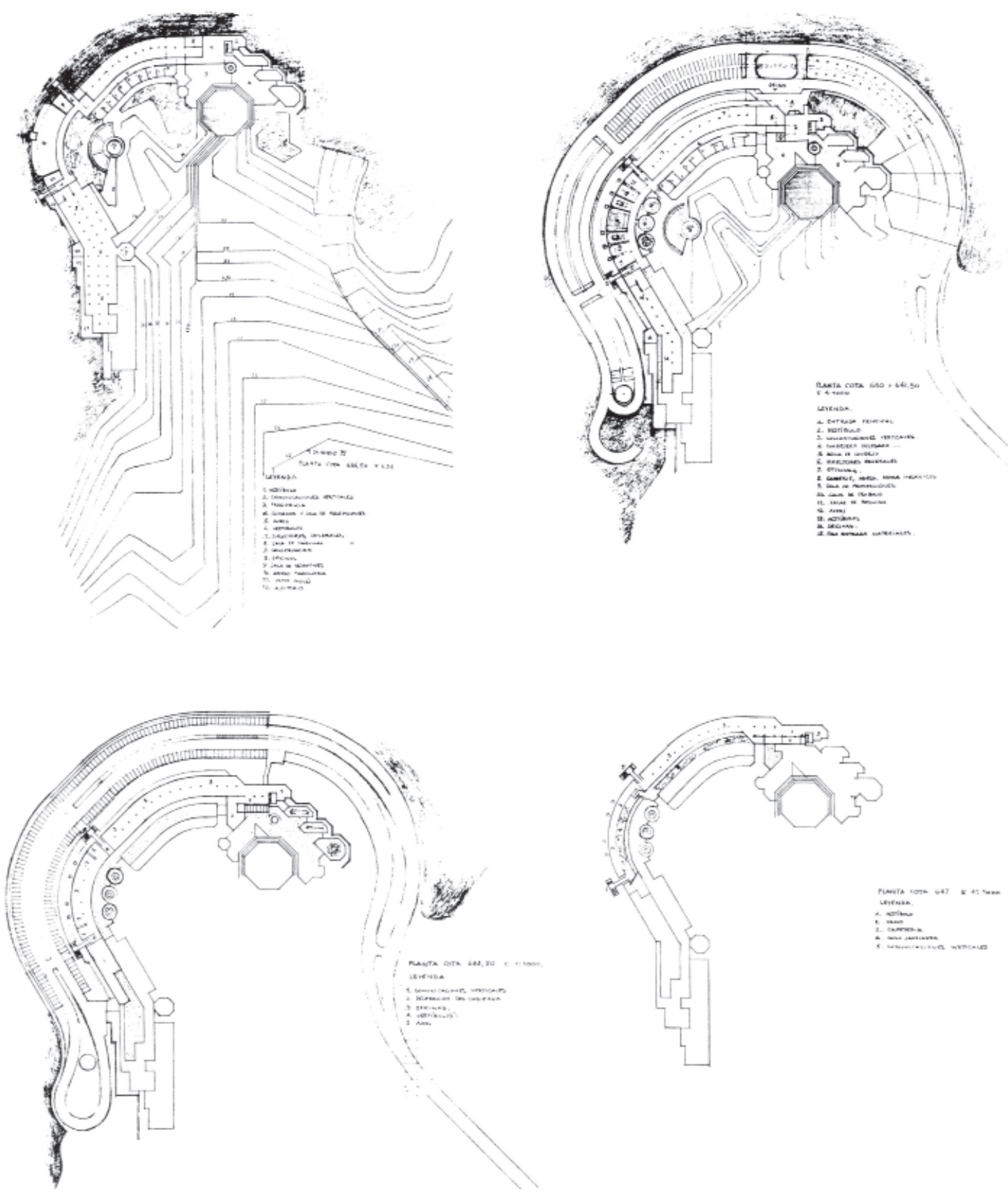


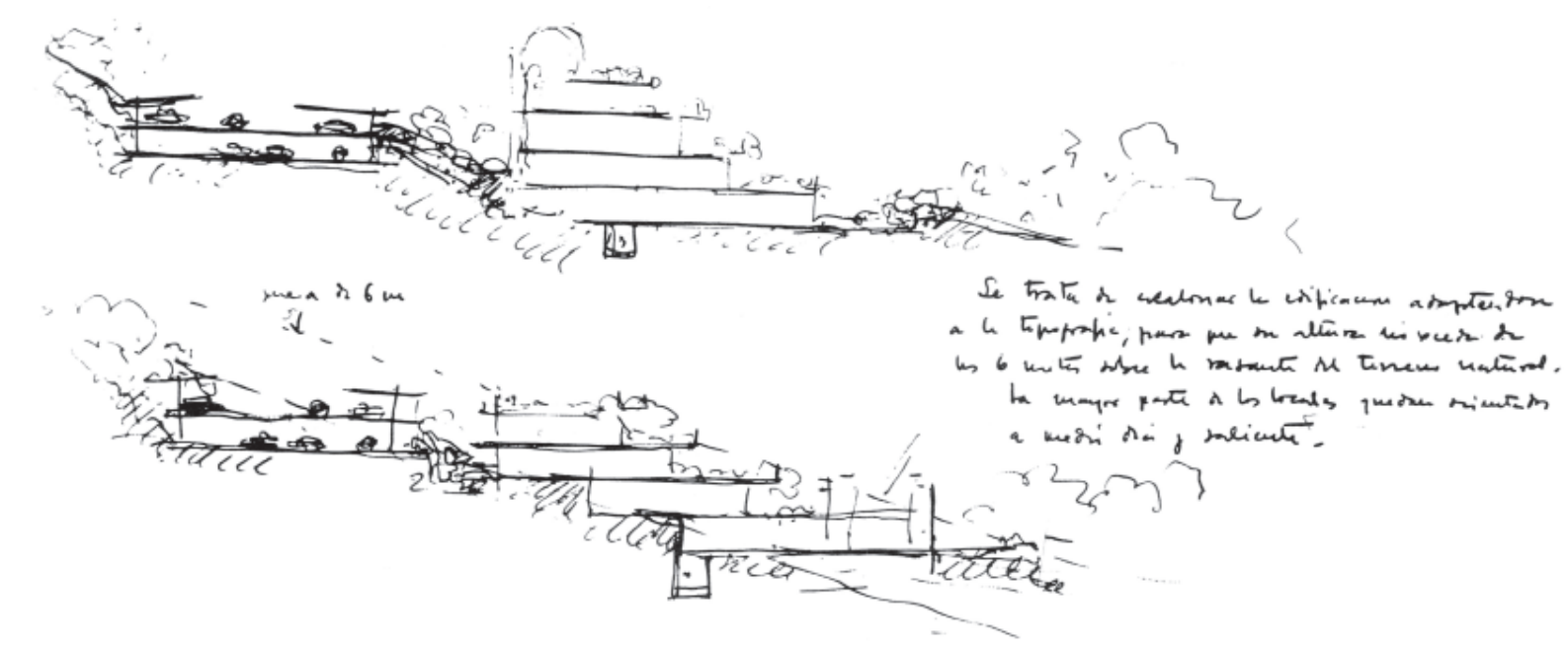

15 Sede Social de Telefónica, propuesta 3; croquis

tiene la adaptación topográfica y se crea una jerarquía direccional por medio de una cabeza orientada hacia el noreste en la que se sitúa la zona de presidencia. La tensión entre unidad y fragmentación se resuelve con una sencilla estrategia de piezas geométricamente individuales agregadas a un cuerpo central lineal de mayor tamaño. Así se observan en planta piezas cilíndricas u octogonales que se destacan claramente del edificio principal, conformado en cambio como un terreno natural de curvas de nivel escalonadas siguiendo el perfil del anfiteatro natural. Esto produce una imagen más urbana que en la anterior propuesta, pero igualmente integrada con el entorno por medio de la vegetación que invade las cubiertas ajardinadas (Fig. 13).

Es extraordinaria la extensión que ocupan dentro de la memoria descriptiva de este anteproyecto (realizado después de la crisis energética de 1973) las consideraciones sobre el acondicionamiento climático por medios pasivos y sobre el aprovechamiento integral de la energía producida en el edificio. Se plantea la climatización con sistemas reversibles (bombas de calor) conectadas a una red y a un depósito acumulador que sirve como volante regulador de todo el sistema que compense en cada momento el balance energético. Se estudian concienzudamente las fuentes de energía para calefacción, con incorporación de placas solares, recuperación de calor residual de los grupos electrógenos, eliminación de calderas, concentradores solares para agua a mayor temperatura, etc., lo que permite hablar a los arquitectos de un ahorro en el consumo energético del $50 \%$.

\section{CONCLUSIONES}

Se ha podido comprobar que los sucesivos proyectos presentan opciones antagónicas en el tratamiento de espacios abiertos y volúmenes construidos, en la materialidad, en la relación entre el interior y el exterior del propio edificio, en su diálogo con el contexto físico y en su orden geométrico. En cambio, resultan completamente convergentes en su lectura exterior como edificios-ciudad y en su tratamiento de los sistemas de acondicionamiento climático - tanto pasivos, como apoyados en la tecnología — como principales generadores de la forma arquitectónica. Estas características, refiriéndonos a proyectos de esa época, fortalecen su vigencia como precursores del auge del paradigma termodinámico en la arquitectura actual (Fig. 14-15).

También queda claro el valor de ejemplo que tienen los proyectos de Fuentelarreina para el estudio del método proyectual de Julio Cano Lasso. Son ejemplares debido a que la invariabilidad del lugar, principal fuente de condicionantes externos para la arquitectura, permite centrar la atención en la propia sintaxis proyectual, en los elementos internos de su método proyectual. Se pone así en valor la gran importancia del método referencial en la configuración de estos proyectos, que permite ser extrapolada al resto de su obra. Gracias a la destilación desde las referencias usadas de herramientas de carácter flexible y dialéctico, se pondera fácilmente en estos ejemplos la gran versatilidad morfológica que permite el método, aun partiendo de unos planteamientos iniciales similares, lo que podría explicar la enorme variedad formal existente dentro de la producción arquitectónica de Julio Cano Lasso, tantas veces destacada por la crítica ${ }^{6}$. 


\section{Notas}

1 Francesco Venezia, prefacio a Julio Cano Lasso-Estudio Cano Lasso (Milán: Electa, 1996), 10-11.

2 Alison Smithson, «How to Recognise and Read Mat-Building: Mainstream Architecture as it has Developed towards the Mat-Building», Architectural Design 44-9 (1974): 573-590. Es tan claro que reproducimos a continuación unos fragmentos: «Un mat-building es aquel tipo susceptible de personalizar el anónimo colectivo, donde las funciones vienen a enriquecer lo construido y lo individual adquiere nuevas libertades de actuación gracias a un nuevo y cambiante orden basado en la interconexión, en los tupidos patrones de asociación y en las posibilidades de crecimiento, disminución y cambio (...). Las partes de un sistema toman su identidad del propio sistema (...) los sistemas tendrán más de las tres dimensiones habituales; incluirán la dimensión del tiempo (...) los sistemas serán lo suficientemente flexibles para permitir el crecimiento y la intercambiabilidad a lo largo de su vida (...) los sistemas permanecerán abiertos en ambas direcciones, es decir, por lo que respecta a sistemas más pequeños dentro de ellos, así como por lo que respecta a sistemas mayores en torno a ellos (...) la ampliabilidad y el carácter de los sistemas serán visibles o al menos averiguables, a partir de la percepción de las partes de los sistemas». Traducción extraída de: Josep María Montaner Martorell, Sistemas arquitectónicos contemporáneos (Barcelona: Gustavo Gili, 2008), 97.

3 Julio Cano Lasso, La ciudad y su paisaje (Madrid: Edición del autor, 1985), 7.

4 La parcela de Telefónica de Fuentelarreina, de 48 hectáreas, se encontraba entre la tapia del Monte del Pardo y la Carretera de la Playa (hoy día se ubicaría en la avenida Cardenal Herrera Oria), al noroeste de Madrid, en una zona de topografía en ladera con predominio de la orientación sur y escasa vegetación. El proyecto, después de las tres versiones reseñadas en este texto, no se llegó a construir. La documentación original de los proyectos sucesivos se ha consultado en el archivo de Estudio Cano Lasso (c/Guecho 27, Colonia La Florida, 28023 Madrid). También hay numerosa información gráfica publicada en: Julio Cano Lasso y Juan Antonio Ridruejo Brieva, Fuentelarreina. Tres propuestas de arquitectura naturalista (Madrid: Edición del autor, 1977); Alberto Humanes Bustamante (ed.), Madrid no construido: imágenes arquitectónicas de la ciudad prometida (Madrid: COAM, 1986); y en Juan Luis Roquette Rodríguez-Villamil, La arquitectura de Julio Cano Lasso, Tesis doctoral inédita (Pamplona: Escuela Técnica Superior de Arquitectura, Universidad de Navarra, 2010), 144-151 (versión 1, 1967), 218-226 (versión 2, 1971), 344-351 (versión 3, 1976).

5 Cano y Ridruejo, Fuentelarreina, 11.

6 Esta variedad formal es destacada en numerosos textos sobre la obra de Julio Cano como: Antón González-Capitel Martínez, «Notas sobre la figura de Julio Cano Lasso en la arquitectura espańola», Arquitectos 123 (1991): 14-21; Juan Daniel Fullaondo Errazu, «En torno a Julio Cano Lasso», Arquitectos 123 (1991): 54-59.

\section{Procedencia de las ilustraciones}

Fig. 01. Julio Cano Lasso. Dibujos y notas 1970-77. Madrid: Edición del autor, 1977.

Fig. 04-05. Julio Cano Lasso. Julio Cano Lasso, arquitecto. Madrid: Xarait Ediciones, 1980.

Fig. 07. Julio Cano Lasso. La ciudad y su paisaje. Madrid: Edición del autor, 1985.

Todas las demás imágenes proceden del libro de Julio Cano Lasso y Juan Antonio Ridruejo Brieva, Fuentelarreina. Tres propuestas de arquitectura naturalista. Madrid: Edición del autor, 1977.

\section{Sobre los autores}

Luis Pancorbo Crespo e Inés Martín Robles son arquitectos por la ETSAM-UPM. Luis Pancorbo es profesor asociado de proyectos en esta misma escuela, y ambos, profesores de ESNE-Universidad Rey Juan Carlos. Han publicado numerosos artículos de investigación en revistas nacionales. Actualmente están desarrollando sus respectivas tesis doctorales, en la ETSAM y la Universidad San Pablo CEU respectivamente. Asociados desde 2005, centran su desempeño profesional en la realización de concursos públicos de arquitectura bajo lema y con intervención de jurado. Habiendo obtenido 17 premios en concursos y 7 premios a la obra construida, esta es la actividad investigadora a la que dedican la mayor parte de su tiempo.

pancorboarquitectos@gmail.com 